\title{
AN APPLICATION OF REPLACEMENT VALUE THEORY
}

\author{
by Prof. A. Goudeket
}

A detailed explanation of the methods used by the Philips Company of the Netherlands to present results of operations in units of constant purchasing power.

The replacement value theory for the calculation of the net income, or loss, and capital of an enterprise, is not yet a generally accepted principle throughout the world. The tendency towards general acceptance of the theory in the Netherlands has gradually developed over a period of forty years. However, the extent to which these principles are reflected in the published financial statements still leaves much to be desired.

In the Netherlands, "sound business practice" is the basis from which both economic and accounting principles and conventions have evolved. While in the United States an " accounting principle" reflects a generally accepted practice, in the Netherlands the yardstick is the concept of "sound business practice."

Both from my contacts with colleagues in the United States and from American publications, I can see that there is still considerable opposition there to replacement value accounting. I am pleased, however, to note that more is currently being said and written in favor of the theory. Both in the United States and in the Netherlands, the accountancy profession has to meet similar problems in the practical application of "accounting principles" and "sound business practice." The actual implementation of neither of these concepts is so definite as to guarantee identical financial presentations.

Consequently, I think it worthwhile to offer some contribution toward an understanding of the subject of the replacement value theory. As I see it, the opposition to replacement value accounting comes from two sources. First, there are those who reject the theory in principle. Second, there are those who accept the principle but who maintain that it is impractical in its application. As to the former, it must be proved that the net income or loss and capital of an enterprise can only be calculated properly if the replacement value theory is adopted. As to the latter, it must be demonstrated that the practical difficulties can be overcome and are not so great as to justify the abandonment of such an important principle.

An article by the Technical Services Department of the American Institute of CPAs, "Opinion Survey on Price-Level Adjustment of Depreciation" (JofA, Apr. 58, p. 36), has led me to conclude that many do not object to the theory as such, but reject it on the ground that, since is not acceptable for tax purposes, the application of the theory is of no importance, quite apart from the fact that its application would involve a great increase in cost as compared with traditional methods of accounting. If these arguments can be refuted, it is possible that the replacement value theory may be considered as a generally accepted "accounting principle" or "sound business practice" in the future.

The best means to overcome objections of a practical nature is to demonstrate both their relative insignificance and the way in which they may be solved. To this end I will give the details in this article of the application of this theory by N.V. Philips' Gloeilampenfabrieken, a large international industrial company with headquarters in Eindhoven, the Netherlands. 
After doing so I will deal briefly with the replacement value theory itself by considering the arguments which are made against the theory in order to give the fundamental bases of the application.

\section{Background}

Before describing the application of the theory in the Philips' concern, it is necessary to indicate the accounting background in which the replacement value is used. Briefly, the principles of the accounting system of the company, which has manufacturing and selling organizations in practically all countries of the free world, may be described as follows:

1. The object of the accounting system is to provide the management of each section of the concern with the information it requires for operating that particular section, and to provide the top management of the concern with the information required for its central management.

2. The accounting system of the concern is organized in accordance with a system of budgetary control which implies the existence of norms and standards.

3. The accounting system is decentralized: each section of the concern has its own accounting department which prepares a balance sheet and an income statement each month for that particular section in accordance with principles followed uniformly throughout the enterprise.

4. In accordance with the principles of "accounting for management", the responsible managers of all levels must know periodically the income and the capital employed, both in total and in detail. For this purpose the replacement value is applied. In other words, the application of the replacement value theory is not merely a calculation technique used in preparing the annual statements of the concern. It is integrated in the accounting system of all sections of the concern at every stage. In this way it is ensured that all information for management is compiled in accordance with this principle, and thus the replacement value automatically enters into all management considerations and decisions.

Needless to say, Philips uses the most modern technical equipment in its accounting system.

\section{Application}

At Philips we hold to the view that there can be no recognition of income for a period unless the capital employed in the business at the beginning of the period has been maintained, that is to say, after it has been established that the purchasing power of that capital at the end of the period is equal to that at the beginning of the period. This problem is dealt with more extensively later in this article.

In giving details of the application of the replacement value theory, the starting point will be the various items making up the capital. Attention will be paid to the way in which the replacement value is determined as well as to its implementation in the accounts.

\section{Fixed assets}

The replacement value is determined on the basis of the trend of the specific price 
levels and not of the general price level: that is to say, the trend of prices is followed separately for buildings, dwelling houses, machinery, etc. Each group of assets is regularly revalued by means of index numbers. For instance, for a factory building, revaluation is on the basis of the index numbers for the cost of that type of building; for machine tools, according to market prices or, if machinery is manufactured in the company's own factories, on the basis of current costs; in cases where the individual machines cannot be classified in homogeneous groups, revaluation is computed item by item. Insignificant price fluctuations are ignored. Larger fluctuations are put through on an approximate basis as and when they arise. Depending upon the importance of the price fluctuations an over-all revaluation per item is put through periodically although not necessarily each year. A department in the Philips organization which is allied to the purchasing department follows the trend in price levels; the accounting department sees to the recording of the individual items in such a way that the information required for revaluation purposes is readily available.

In connection with the application of replacement value in the accounting system, the following accounts are kept: (1) accounts of fixed assets at replacement value; (2) accounts of the depreciation of fixed assets at replacement value; (3) revaluation-surplus for fixed assets; and (4) cost of depreciation of fixed assets.

The accounts under (1) and (2) belong to the group of fixed assets accounts; account (3) is a capital account; account (4) is an income account. By entering every revaluation into the accounts, account (4) will automatically be charged for the depreciation on the basis of replacement value, since the depreciation is a function of the value of the assets and their lives.

If a price increase occurs, the accounts under (1) are increased to the current price level with the account (3) as a contra account. The accounts under (2) are dealt with in the same way. In respect to the latter, however, the following should be noted. The revaluation of the depreciation accounts demonstrates that with an increase in price level the depreciation provided in previous years has been too low. Therefore, this must be increased in order to provide for complete depreciation of the fixed assets on the basis of the present price level at the end of their useful life, and to insure that adequate funds for replacement will be available. This revaluation of past depreciation should therefore be charged to the income account. In the Philips company this is not done for two reasons, namely:

1. Due to the size of the concern the composition of the total fixed assets as far as lives are concerned approximates an average. As a result, yearly replacements for all practical purposes are equal to the yearly depreciation. This implies that the capital invested in fixed assets always relates to the total of fixed assets of an average life and no deferred depreciation needs to be provided for.

2. Against the income account a fund is being built up to provide for the maintenance of capital invested in assets which are hereafter referred to as "monetary assets", representing assets other than inventories, fixed assets, investments and intangibles. This problem will be dealt with later.

In case of a decline in price levels, the procedure followed is the opposite of what is done in the case of an increase. In the case of a decrease, it must first of all be firmly established that the decrease is the result of a changed price level. If the 
decrease results from other economic or technical reasons, the decrease must be charged to the profit and loss account. Should the revaluation account be completely exhausted as a result of charges on account of price decreases, then the adjustment of the replacement value will be charged to the income account, since it is a rule that the revaluation reserve may never show a debit balance.

\section{Inventories}

It has already been stated that within the scope of the application of the budgetary system in Philips, standard prices are in operation for all groups of inventories, that is to say for goods purchased, for semi-finished products and for finished goods. For the establishment of the replacement value the starting point is the price level which formed the basis for the calculation of the standard prices. The trends in the price levels of the various elements of the standard prices are followed and their effect on the standard prices is calculated. Whenever the fluctuation in price levels is material enough to cause an inventory adjustment, the standard prices are adjusted to replacement value by means of index numbers. Individual adjustments of standard prices take place periodically, yearly, or at longer intervals if there is no reason for an adjustment at the end of a particular year. In view of the volume of work involved, the decision for an individual adjustment of prices is taken with care, having in mind the large degree of integration which exists in Philips.

The organization for the calculation of index numbers can be described as follows:

a. The calculation of index numbers is part of the duties of an estimating department.

b. The purchasing department keeps records of the purchase prices of the main raw materials on the basis of market quotations, tenders, recent purchases and the like, and informs the estimating department regularly of all price changes.

c. On the basis of the information under (b) the estimating department has at its disposal up-to-date price records.

d. For its own purposes and on behalf of other departments which require current information on prices, the estimating department keeps a so-called rough price list of the major articles purchased. By means of lists of price changes which are serially numbered, these lists are kept up to date. They contain the following information:

Code Number

Description of the Article

Fixed Price as at ........

Adjustment Number........

as at ........

price

index

Adjustment Number........

as at ........

price

index 
e. The estimating department also keeps a more detailed price list in which related articles are classified in groups. The index numbers for the articles appearing in the rough price list determine the index numbers of the entire related group.

f. For labor and overhead, the index numbers are calculated on the basis of the trend of the price levels of wages and expenses. As far as expenses are concerned, the changes are not calculated to the very last detail; capacity costs are given major attention.

g. For the calculation of the index numbers of the company's own production, covering both semi-finished and finished products, the estimating department has the following data at its disposal:

(1) standard prices and index numbers of purchased articles

(2) standard prices and index numbers of products of supplying departments

(3) standard prices and index numbers of rates for man and machine hours of the related production unit

h. In the case of the company's own production, also, the index numbers are not calculated by individual article. By an appropriate grouping of the articles, the index number of one or some prototype(s), which is (are) the article(s) representative for a whole group, is calculated. This index number is applicable to the whole group.

In the accounting system the following accounts are kept: (1) inventory accounts; (2) adjustment accounts to reflect changes in index numbers; (3) price difference accounts; and (4) revaluation-surplus for inventories. The accounts (1) and (2) are accounts for current assets, (3) is an income account, while (4) is a capital account.

Inventory accounts are kept at standard prices. If an interim revaluation takes place, account (2) is debited and account (4) is credited. After revaluation the inventory movements are valued at standard price times the index and the relative entries are posted to accounts (1) and (2). This means that on a purchase both accounts are debited and that account (3) which formerly was debited or credited for the difference between purchase price and standard price is now used for the difference between purchase price and standard price plus the index adjustment. In respect of goods consumed, accounts (1) and (2) are credited; in respect of production both accounts are debited.

\section{Index adjustment accounts}

Every division with an individual balance sheet and income account keeps separate accounts for the index adjustment on raw materials, fwork in process and finished products.

On the basis of the last index at the end of the financial year for inventories, the revaluation is recalculated. If the amount thus calculated differs from the balance of the index accounts, these accounts are adjusted to the debit or credit of the income account. Dependent upon the amount of the difference, an analysis is made prior to passing the relative entry through the books.

If the standard prices are changed, then the difference is posted to the contra of the revaluation surplus. The balance of the entries on account (2) which so far have been made on that account is reversed to the debit of account (4). If large 
differences occur between the two entries, an anlysis of them is made. Thus the index accounts have in principle been absorbed in the inventory accounts as a result of changing standard prices.

The procedure in the case of a decrease in price level has been indicated under fixed assets.

With regard to the foregoing, one further observation should be made. When revaluing own-manufactured products, consideration is given to the fact that the trend in prices is also affected by changes in technology. With a continuous improvement in efficiency, this element will have a retarding effect on the increase of the price level. Since it may be assumed that the general technological price decrease will have affected the general price level, a calculation is made of the effect which a higher rate of efficiency in the company's own factories has had on the level of our costs. The price decrease rosulting therefrom is charged to the income account and not to the revaluation surplus.

Needless to say, inventories are never revalued above the amount at which they can be sold at a profit. The diagram of entries (pp. 350-351) may serve to further explain the foregoing.

In conclusion, a few words should be said about Lifo. It is true that the Lifo method may be looked upon as an approximation of the replacement value principle as far as the income statement is concerned. The Lifo system, however, is a reasonably acceptable solution only if there is a high rate of turnover of inventories and if inventories do not decrease in volume. The major disadvantage of the Lifo method is that no standard prices based on current price levels are used, as a result of which the information for management must be inadequate in several respects. Examples of such inadequacies are that in the income statement efficiency variances and price differences are mixed up, and that in the balance sheet the real capital employed is not presented.

\section{Investments}

With regard to investments, the explanation can be brief. As far as consolidated subsidiaries are concerned, the principles of the parent company are also followed by the subsidiaries. For the other investments we recommend that the companies keep the accounts along similar lines, since the principles, as already explained, are also appropriate for internal management policy. In those cases where nevertheless these principles are not applied, the investments are included in our own accounts as nearly as possible in accordance with these principles, on the basis of information obtained from the affiliates.

\section{Intangible assets}

In its external reports Philips includes intangible assets at no value, so that revaluation problems do not occur. As regards the treatment of these accounts internally, particular mention should be made of initial costs. These represent expenditures made in connection with the starting up of production of new products, which expenditures are recovered in a certain period out of a precalculated volume of production. The revaluation of this asset is similar to that of inventories.

\section{„Nominal assets" financed with stockholders equity}

As already mentioned, we in Philips believe that there can only be profit if, 
after the application of the replacement value theory, the purchasing power of stockholders' equity has been maintained. The details of the procedure are given below on the basis of a classification of the balance sheet directed at this problem.

\section{Balance Sheet as at the beginning of the period}

inventories, fixed and intangible assets, and investments "monetary" assets (as previously defined)

$$
\text { stockholders' equity }
$$

c

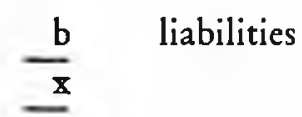

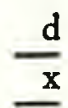

Inventories, fixed and intangible assets, and investments are revalued according to the procedure set forth above. Since part of the stockholders' equity is invested in other (monetary) assets, the purchasing power of that part will diminish in case of a decrease in value of currency of the country. For this reason we calculate, on the basis of the cost-of-living index, how many currency units represent the same purchasing power as the part of capital which at the beginning of the period was invested in "monetary" assets. In the example given, this amount equals b-d. This balance, multiplied by the inflation-factor based on the cost-of-living index, leads to the entry:

\section{Dr. Cost of inflation}

(income account)

Cr. Reserve for diminishing purchasing power of capital invested in monetary assets

(capital account)

Thus the income statement shows a result after the purchasing power of stockholders' equity has been maintained.

When making monthly balance sheets and income statements, the necessary information is always available at short notice. The intervals at which the calculations are made are determined by the pace at which the currency of the country is decreasing in value; the faster this pace, the shorter the intervals will be.

The foregoing should logically imply that in the case of an increase in the purchasing power of money, a profit should be recorded. With regard to this aspect, the company follows this rule: profits may be recognized to the extent that past losses of this nature have been shown. The profit to be taken is therefore limited to the maximum of the balance of the account for diminishing purchasing power in "monetary" assets.

In principle, no limit would be required for crediting the income account to the debit of the reserve for diminishing purchasing power of capital invested in nominal assets. However, in that case it would be possible that the said account would show a debit balance. Here as well it is a rule that this account may never show a debit balance.

If and under what circumstances the element of inflation of "monetary" assets should be included in the calculation of costs is a problem which may be left out of discussion in this article. 


\section{Diagram of Entries}

INVENTORIES

\begin{tabular}{l}
\hline DESCRIPTION \\
1. Revaluation by \\
means of index \\
numbers: \\
a. raw materials \\
in stores \\
b. work in pro- \\
cess \\
c. finished pro- \\
ducts in stores
\end{tabular}

2. Purchases

3. Movements of stock within the company:

a. initial work in process

b. consumption for production

c. production

d. final work in process

e. delivery to other departments

f. delivery from other departments

4. Consumption goods sold

5. Recalculation index accounts

6. Change of standard prices:
a. change
b. transfer ba- lance index $\mathrm{a} / \mathrm{c}$
c. technological influence

\section{Raw \\ Materials}

Changes Ind. Numbers

Rawe Materials

Work

in Process

Changes Ind. Numbers

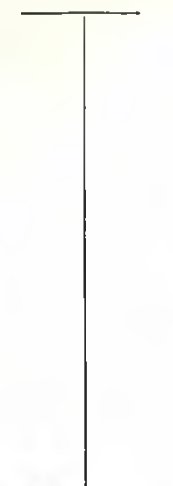

a

b

a

Work in Process
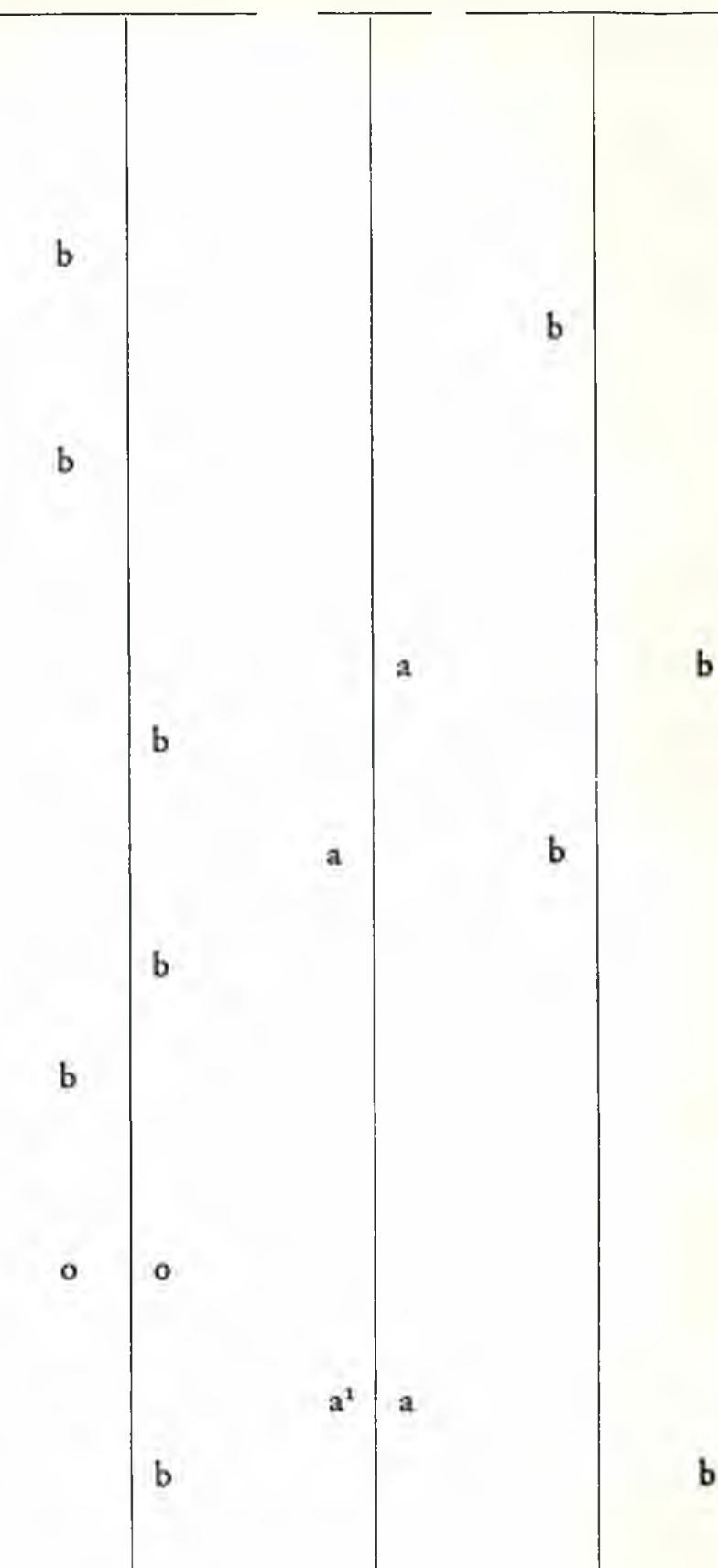

a

a

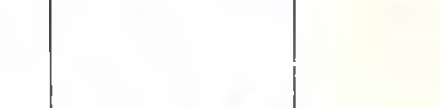

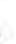

b

Note 1: a = standard price

$b=$ changes index numbers

$p=$ purchase price

Note 2: simplifications are introduced depending on circumstances. 


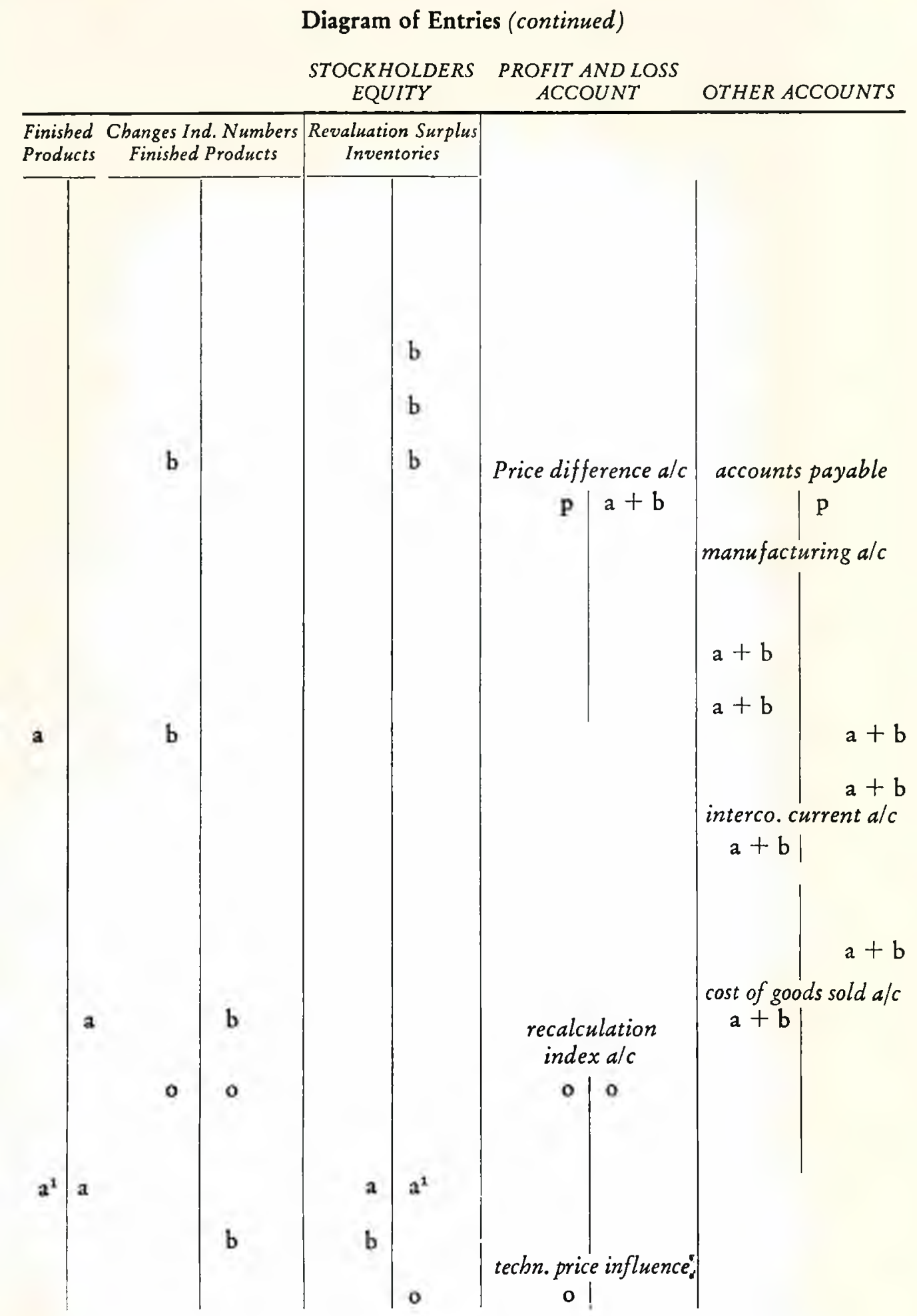

m a b blz. 351 


\section{Foreign currencies}

With an international concern such as Philips, the rates of exchange of foreign currencies are of such importance that, although only indirectly connected with revaluation, they must be discussed. In general we at Philips follow the principle that assets and liabilities in foreign currencies should be converted at the rates of exchange at the balance sheet date. Each unit within the company does this in its own accounts. Exchange differences are charged or credited to the income account.

In connection with revaluation, the problem which requires special attention is the establishment of the rates of exchange of currencies for the computation of the value of foreign investments in the annual financial statements of the parent company and in the consolidated statements. The economic research department works on this problem. The maximum rate of exchange used for conversion purposes is the official quotation. Foreign exchange rates are under continuous investigation in order to determine, country by country, whether its internal economic situation, the international position of its currency, or other considerations, such as restrictions of transfers, might indicate the desirability of using conversion rates other than official rates. In these cases rates are established in which the trend of the relationship between the purchasing power of the currency of the country concerned and of the Netherlands is carefully considered. At Philips, rates of exchange calculated in this way are called "purchasing power rates."

Since in general there is a relationship between the trend of the price level in a country and the fluctuations in the rate of exchange of its currency, the following procedure is applied in the valuation of investments: the balance sheet of the foreign subsidiary is converted at the established rate of the country concerned. If this rate is lower than the one at the previous balance sheet date, as a result of which the net worth of the affiliate, calculated in the currency of the parent company, is lower than the intrinsic value of the investment according to the books, this difference-being an unfavorable exchange difference-is set off as far as possible against the amounts which the affiliate in the course of the financial year has credited to the revaluation surplus and to the account for the diminishing purchasing power of capital invested in "monetary" assets. The remaining balance of the exchange difference account is transferred to the income account.

Occasionally the balance sheet of a subsidiary, after elimination of intercompany balances, shows a credit balance for capital invested in "monetary" assets; that is to say, it has more debts owing to third parties than accounts receivable and liquid resources. In such a case, conversion of the foreign currency at a lower rate than the official quotation would not be economically correct. Although from a legal point of view the parent company is not required to provide for a possible shortage of liquid assets, since this will be the case economically, a provision is made for the difference between the purchasing power rate and the official quotation, calculated on the credit balance concerned.

It is generally acknowledged that the currency problem is a very complicated one. We believe that by the procedure adopted we have succeeded in showing the losses due to inflation and finding a solution which is as simple as possible and which serves the determination of income and capital. 


\section{Taxation of income}

Taxation of income is concerned in the revaluation in two ways. First, the income calculated according to the replacement value theory will differ from taxable income, since in a vast majority of countries the tax authorities do not accept (or only partly accept) the replacement value theory. In periods of rising prices the taxable income will be higher than the income on the basis of replacement value. Since the provision for taxation must be at least equal to the amount actually to be paid, the burden of taxation will be heavier than if the rates of taxation were applied to the economic profit. Since a later settlement of this excess cannot be expected within a reasonable period, it is not possible to carry forward a latent claim, and this does not therefore offer compensation for the heavier burden of taxation. In the second place, the taxation deserves attention in connection with the entering of the revaluation in the books.

Since the total net worth as shown in the balance sheet must be "free of tax", while the tax authorities do not assess taxation on this revaluation, the following procedure is used:

a. When making the entry for the revaluation, the group of accounts representing net worth is credited for the revaluation. After that the revaluation surplus is debited for the latent taxation on the revaluation, which is entered as a latent liability.

b. To the extent that revalued assets are absorbed in the income account and thus are brought into the tax sphere, the latent liability is transferred to the revaluation surplus.

A correct picture of the total capital invested is thus maintained while in respect of net worth the basic principles are followed, that is to say, that net worth has to be free of tax.

\section{General aspects of the theory}

The management of a business enterprise, its shareholders, and the public require information on the operation of the enterprise, both as a picture of past performance and as an indication of future possibilities. Thus we are confronted with problems of internal and external presentation of information having both retrospective and prospective objectives. This information is required for internal use not only for managing the enterprise but also for the effective daily operation of its affairs at all levels in the organization. For external purposes the management renders an account of its stewardship and supplies any other information on the operations and prospects of the enterprise which may be considered useful.

This implies that the method of calculation of the income and capital must be the same for both purposes and that the reports for both purposes may vary only as to the details of information and frequency of issuance. There is therefore no reason to make any further distinction between internal and external requirements.

The paramount importance of the replacement value theory is a direct result of the economic phenomenon of changing price levels. These changes may be either of a specific nature, that is to say in respect of specific commodities, or of a 
general nature, arising from the purchasing power of money. This raises problems of valuation and their effect on the calculation of income and capital.

Distinction has to be made between changes of a capital nature (which economically do not form part of income) and income itself. As regards the income itself, a distinction must be made between the operating income and sundry revenue and expenses. Let us now consider the operating income.

It is a truism that the operating income of an enterprise during a certain period is properly reflected in the income statement only if it shows the revenue of the period and the cost which has been incurred to produce it. The replacement value theory contends that, in order to assure the continuity of the enterprise, all costs incurred must be included in the income statement at their replacement values and not at the prices which actually may have been paid. It is irrelevant whether or not replacement is actually taking place at the moment the cost is incurred. The replacement value particularly plays a part in establishing the amounts of cost incurred when absorbing raw materials and fixed assets in the product and also in establishing the cost of finished products in sales. It should be noted that the replacement value theory is applicable not only to the cost of fixed assets (depreciation) and materials but also to wages and all other elements of cost.

I disregard the fact that the enterprise with a view to its inventory policy and its expectations regarding the fluctuation of prices may operate in the commodity futures market. The results of such operations will have to be shown separately.

Apart from the obvious argument regarding the continuity of the enterprise, the fallacy of calculating the results on the basis of historical cost becomes evident when one compares the results of a company which happened to be formed in a period of low price levels with those of one not in such a position. The same applies if the company disposes of goods obtained during a period of a lower price level. (The fact that both companies may employ the Lifo principle with respect to inventories is only a partial rebuttal to this argument.)

In fact, however, it is indisputable that the operating results of both companies for that particular period are the same. Although the difference between the so-called historical result and the actual operating result does not represent income, it is true that there is an increase of capital, but this has no bearing on its earning capacity. This should be apparent from the financial statements prepared both for internal and external purposes.

\section{Dividend policy}

The replacement value theory is also important in relation to a company's dividend policy. When profits are computed on the basis of historical cost, there is a risk of distributing dividends which represent not only profits, but also part of the funds required for replacements, and, consequently, for the continuity of the enterprise. If all the historical profits were distributed to shareholders, it might result in the enterprise eventually having to go into the capital market for funds with which to maintain the same volume of business. Some of my American colleagues contend that a well-managed enterprise will of course retain a part of its profits for replacements, and that the ultimate position in both cases is the same. The difference, however, is that in the one case only that amount is shown as a profit which can be distributed without danger to the continuity of the enterprise, whereas in the other case a larger amount is disclosed as a profit which, if 
completely distributed, might endanger the continuity of the enterprise. Even if the distribution of the profits were to be the same in both cases, the historical basis would show a larger profit and a larger profit retention than by replacement value. In my view this would create an entirely wrong impression.

The replacement value theory also results in a clear-cut measurement (quantification) of those elements which are otherwise left to guesswork by individuals. Taking into account that especially in the United States modern economic concepts tend more and more to measurement of economic problems and their effects, this is another important advantage resulting from the adoption of the replacement value theory. The point is sometimes made that informed readers of financial statements understand the principles on which they are based, and the shortcomings of those principles. Hence, they make mental adjustments for such things as replacement values. This adjustment, however, cannot be considered an acceptable compensation.

The replacement value theory also plays a role in a company's selling-price policy to the extent that costs are a basis for the determination of the selling prices. Selling prices are also determined by competition, but until competition makes itself felt, selling prices are based in part on costs. The replacement value theory therefore may have a direct bearing on the gross income of the enterprise.

\section{Employment of invested capital}

The replacement value theory is also important in measuring the effective employment of invested capital. If the information on profits is not measured against the real capital employed, then the information is inadequate. The ratio of profits to capital is an important indicator both for the management of the enterprise and for the investor. However, if the capital is not calculated on the basis of replacement value, then the profits are measured against a capital which has little economic meaning. If capital is not adjusted to reflect replacement value, it is nothing but an arithmetical balance on which no opinion of the earning capacity can be based.

\section{The foregoing can be summarized as follows:}

1. There can only be income if the costs incurred in the production of revenue are included in the calculation of income in such amounts that replacement can be effected.

2. A correct picture of the real capital employed in the business can only be given if assets and liabilities are calculated on the basis of current price levels.

Much attention is given to the distinction between earned and capital surplus. Therefore it is all the more obvious that the increase in capital due to the rise in price levels should not be shown in the balance sheet as part of earned surplus. The use of the replacement value theory will automatically achieve this desired result.

It will be noted that, because of existing circumstances, I have discussed the problem chiefly in terms of rising price levels. Exactly the same considerations, however, apply in the case of falling price levels. In the latter case there is also the need to distinguish between operating results and gains or losses due to changes in price levels, and for judging the effective employment of capital. 


\section{Tax considerations}

I think it is clear that tax considerations play an important part in the thinking of many persons who are opposed to the replacement value theory; in my opinion, this is not justified.

It is true that in many countries taxes are calculated on the basis of historical cost. In some countries certain provisions in the tax statutes and regulations exist, the use of which reduce the effect of changing prices (e.g. the Lifo inventory method). This does not imply, however, that accounting followed for tax purposes should also be employed for management purposes or for financial reporting purposes. It is not unusual for major differences to exist between a company's tax returns and its published financial statements. If the replacement value theory is accepted, then it must be conceded that to use tax principles in the accounts is to knowingly disclose an incorrect picture of income and capital which might lead to wrong impressions and decisions. If it is thought appropriate, the variation in taxation resulting from a difference in economic and taxable profits can be shown separately in the annual financial statements.

There is still another reason why advocates of the replacement value theory in particular should not employ tax principles in the accounts. It would, of course, be desirable if the tax authorities too would accept the replacement value theory. However, one cannot expect the tax authorities to do so, or rather to convince them that they should do so, if one follows tax principles for management purposes and for the information of the public.

It seems to me that one demonstrates the great importance of an economically correct presentation by applying it both in the accounting system and in the published annual statements, and by so doing, one may hope to succeed in changing the views of the tax authorities.

I have not discussed many of the details relating to the fundamental aspects and the application of the replacement value theory. In this article it was not intended to deal with the problems from a theoretical angle. My only aim was:

a. To change the opinion of opponents through stating our case;

b. To show supporters of the theory that the practical difficulties involved need not deter them from adopting the theory.

\section{Conclusions}

1. We know that in Philips we do not apply the replacement value theory in all its details. Certainly theorists can criticize our application in some respects. As with all problems, it is not a question of the application of the theory in all its details; it is only a question of a practical application based on theoretical principles. Then a need is being fulfilled. In practice it is not the problem, but its solution, which counts.

2. Without the application of the replacement value theory we would feel a great uncertainty in our management. The segregation between operating results related to transactions or periods on the one hand, and other changes in capital, such as differences resulting from changes in price levels, on the other hand, is essential for management. The information in respect of capital in- 
vested is indispensable for financial purposes and for the appraisal of earning capacity. Intercompany comparisons and comparisons of subsequent periods would be unreliable without replacement value.

3. It is not possible to make a calculation which shows the cost connected with the application of the replacement value. Modern accounting methods and equipment reduce the extra cost to a minimum. Of far greater importance is the conviction that a more appropriate basis for policy decisions is created, and that is of tremendous value. The extra cost is certainly negligible as compared with this benefit.

4. It is not desirable to take a different view with respect to external and internal information. The difference between internal and external information is not of a fundamental nature; it concerns the conception but not the results.

5. We have often noted that financial analysts, when dealing with the annual report of Philips, did not look upon the revaluation surplus as a capital account but deducted the amounts from the assets concerned. After the foregoing explanations it will be obvious that we believe this to be basically incorrect. But even if one feels the need for comparison purposes to classify the Philips annual report figures according to a traditional method, one must realize that a very large part of the revaluation has been absorbed in the profit and loss acount by way of depreciation of fixed assets and goods consumption, as a result of which that portion of the revaluation surplus must be regarded as earned surplus.

6. Our belief in the correctness of the application of the replacement value is emphasized by consciously accepting a less favorable demonstration of the financial position in the annual report as compared with other enterprises which adhere to a traditional method.

a. In the long period of increasing price levels in which we are living, the profits shown by Philips are less favorable than according to a traditional method.

b. The net worth is larger, as a result of which the ratio of profit to net worth is less favorable.

c. Even if, after distribution of profits, the position according to the two methods is the same, under a traditional method this position is achieved with a larger income and larger retained earnings, which for the superficial reader gives a more favorable picture than under the application of replacement value. 